\title{
Interpretation of Upper Gastrointestinal Tract Mucosal Biopsies - A Tertiary Care Centre Experience
}

\author{
Sadhana L Kothari ${ }^{1}$, Anupama Dayal ${ }^{2 *}$ and Shanti. M. Patel ${ }^{3}$ \\ ${ }^{1}$ Associate professor, Pathology Department, GCS Medical College Hospital and Research Centre, Ahmedabad, Gujarat. India \\ ${ }^{2}$ Associate Professor, Pathology Department, GCS Medical College Hospital and Research Centre, Ahmedabad, Gujarat. India \\ ${ }^{3}$ Professor and Head, Pathology Department, GCS Medical College Hospital and Research Centre, Ahmedabad, Gujarat. India
}

\section{ABSTRACT}

Background: Endoscopy is one of the initial diagnostic tests performed for the evaluation of upper gastrointestinal (GI) symptoms in clinical practice. Accurate interpretation and confirmation can be achieved by histopathological study of endoscopic biopsies and is one of the bases for planning proper treatment.

Methods: Total 200 endoscopic biopsies, 50 from oesophagus, 50 from stomach and 100 from duodenum received in the department of pathology of a tertiary care medical college and hospital, Ahmedabad, Gujarat, India, over a period of two years from patients of all ages and sex with upper GI symptoms were included. Specimens were processed according to standard protocol and then reported by pathologist. The spectrum of histopathological lesions, whether inflammatory, non - neoplastic or neoplastic was evaluated along with the overall frequency, age and sex distribution of various upper gastrointestinal lesions.

Result: Out of 200 cases of endoscopic biopsies received, 114 were males and 86 were females (M:F- 1.3:1). Majority were non-neoplastic lesions comprising of $153(76.5 \%)$ cases. Out of 38(19\%) malignant cases, oesophagus was the most common site comprising 78.9\% and duodenum was the least common site comprising $10.5 \%$ of total malignancy. In duodenum $25 \%$ cases of celiac disease were also identified.

Conclusion: In this prospective study, the commonest site for upper GI endoscopic biopsy was from the duodenum (50\%). Overall Inflammatory lesions were more common (76.5\%), the predominant sites being stomach (88\%) and duodenum (68\%). Most common site for malignancy was oesophagus, histological type was Squamous Cell Carcinoma predominantly. Endoscopic biopsy serves as an effective tool for the diagnosis and management of upper gastrointestinal lesions.

\section{Keywords: Upper GI, Endoscopy, Biopsy, Inflammatory}

\section{Introduction}

Various pathology involving the upper Gastrointestinal (GI) tract manifest with a similar group of symptoms which may be difficult to assess clinically. There are several diagnostic investigations available in the evaluation of these symptoms where endoscopy is performed as the initial diagnostic test. ${ }^{[1]}$ Endoscopic screening may detect mucosal lesions at an early stage especially atrophy, intestinal metaplasia and dysplasia so as to prevent progress of lesions to invasive cancer. ${ }^{[2,3]}$

Endoscopy with biopsy and histological examination is more rewarding than endoscopy alone ${ }^{[4]}$ as more accurate and detailed information results from histological examination of mucosal biopsy specimens. ${ }^{[5]}$ In routine clinical practice histology is often considered as the 'Gold standard' against which other tests are performed. ${ }^{[6]}$

In this study the nature and frequency of different upper gastrointestinal lesions, benign or malignant, diagnosed on endoscopic biopsy, in different age groups was evaluated.

\section{Materials and Methods}

The present study was carried out in department of pathology of a tertiary care medical college and hospital, Ahmedabad, Gujarat, India from January 2016 to December 2017. Total 200 endoscopic biopsies, 50 from oesophagus, 50 from stomach and 100 from duodenum were collected from patients of all ages and sex with upper GI symptoms and included in the study. Biopsies from lesions of mouth, pharynx or jejunum and below were excluded. The demographic data was collected from the clinical records of the patient. Majority of oesophageal biopsies were from thickened area, friable growth and ulcerated area in middle and lower part of oesophagus. Gastric biopsies were predominantly from antrum and body of stomach. All the duodenal biopsies were taken from second part of duodenum (D2) showing scalloping, nodularity or growth.

All tissues were fixed in 10\% formaldehyde, routinely processed in an automatic tissue processor and then paraffin wax blocks prepared. Three to five serial sections of four to five micron thickness were cut, stained with Hematoxylin 
and Eosin and then analyzed microscopically by a pathologist. Special stains like PAS and Giemsa's stains were used in selected cases to rule out /confirm H.pylori and other lesions. Adequacy of biopsy was assessed and tumours were classified according to WHO classification.

Grading of duodenal biopsies was done according to modified Marsh Classification. ${ }^{[7]}$

The clinical \& histopathological data so obtained were statistically analyzed using Microsoft Excel software.

\section{Result}

Out of 200 cases of endoscopic biopsies received, majority were from duodenum accounting for 50\% (100) of total, biopsies from oesophagus $(n=50)$ and stomach $(n=50)$ comprised $25 \%$ each. There were 114 male patients and 86 female patients (M:F- 1.3:1).

Table 1 shows the distribution of upper GI lesions according to age and site. Highest no. of biopsies ( $\mathrm{n}=73,36.5 \%)$ were performed in 51-70 yrs, followed by 54(27\%) biopsies in $31-50 \mathrm{yrs}, 52(26 \%)$ in $0-30 \mathrm{yrs}$ and lowest were in $70-90$ yrs $(\mathrm{n}=21,10.5 \%)$.

Non-neoplastic lesions comprised of 153 (76.5\%) cases out of which histologically the predominant lesions seen were: chronic duodenitis $(\mathrm{n}=68,34 \%)$, non specific gastritis $(n=27,13.5 \%)$, Celiac disease $(n=25,12.5 \%)$ and oesophagitis $(\mathrm{n}=12,6 \%)$. Premalignant lesions, histologically evident as dysplasia, were seen in $9(4.5 \%)$ cases; 5 in oesophagus and 4 in stomach. Out of $38(19 \%)$ malignant cases, oesophagus was the most common site comprising $78.9 \%$ (30/38) of total malignancy.

In oesophagus out of 50 cases, malignancy was more common accounting for $60 \%$ (30/50) of the cases. Dysplasia was seen in 10\% (5), Barret's oesophagus in 6\% (3) and oesophagitis in 24\%[12] of cases. (Table 2) Amongst the malignant cases Squamous Cell Carcinoma (26/30,86.6\%) was more common than adenocarcinoma $(4 / 30,13.4 \%)$. Majority of Squamous cell carcinomas detected were moderately differentiated $(\mathrm{n}=17,65.4 \%)$.

Most of the gastric lesions encountered were inflammatory $(\mathrm{n}=44,88 \%)$ showing Chronic Non specific gastritis in $54 \%$, H.pylori induced gastritis in $12 \%$, erosive gastritis in $6 \%$, chronic gastritis with intestinal metaplasia in $8 \%$ and chronic gastritis with dysplasia in $8 \%$. Gastric polyp was seen in $4 \%$ of cases. All the $4(8 \%)$ malignant cases were of adenocarcinoma. (Table 3)

Malignancy was least common in duodenum comprising $4 \%$ of cases whereas nonspecific duodenitis was most common (68\%). 25 cases of Coeliac disease were detected and classified according to modified Marsh Classification. Type IIIA was the most common (10\%), followed by Type IIIB (7\%), Type II $(6 \%)$ and Type I $(2 \%)$ in that order. (Table 4)

Table 1: Distribution of Upper Gastointestinal Lesions According to Age and Site.

\begin{tabular}{|c|c|c|c|c|c|c|c|c|c|c|c|c|c|c|c|c|}
\hline \multirow[b]{2}{*}{ 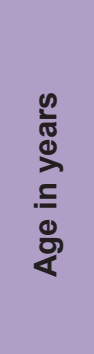 } & \multicolumn{4}{|c|}{ Oesophagus (50) } & \multicolumn{7}{|c|}{ Stomach (50) } & \multicolumn{4}{|c|}{ Duodenum (100) } & \multirow[b]{2}{*}{ Total } \\
\hline & $\begin{array}{l}\frac{n}{ \pm} \\
\frac{5}{\pi} \\
\frac{0}{0} \\
\frac{0}{0} \\
0 \\
0 \\
0\end{array}$ & 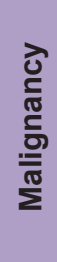 & $\frac{\frac{\pi}{0}}{\frac{\pi}{0}}$ & $\begin{array}{l}\frac{\pi}{0} \\
\frac{\pi}{0} \\
\frac{0}{0} \\
\frac{\pi}{0} \\
\sum\end{array}$ & 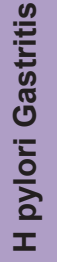 & 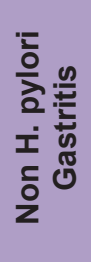 & 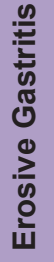 & $\begin{array}{l}\text { ত̀ } \\
\frac{c}{\sqrt{0}} \\
\frac{5}{5} \\
\frac{0}{\bar{N}} \\
\sum\end{array}$ & $\frac{0}{\overline{0}}$ & $\frac{\frac{\pi}{0}}{\frac{\pi}{0}}$ & 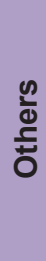 & 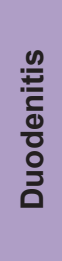 & 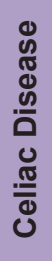 & $\begin{array}{l}\text { ত̀ } \\
\frac{c}{\sqrt{0}} \\
\frac{5}{0} \\
\frac{\sqrt{\pi}}{\Sigma} \\
\sum\end{array}$ & $\begin{array}{l}\frac{\infty}{d} \\
\frac{5}{0}\end{array}$ & \\
\hline $0-20$ & & & & & 1 & 1 & & & & & & 9 & 5 & & & 16 \\
\hline $21-30$ & 2 & 2 & & & 1 & 4 & 1 & & & & 1 & 16 & 9 & & & 36 \\
\hline $31-40$ & 1 & 2 & & & 1 & 4 & & & 1 & & & 10 & 2 & & & 21 \\
\hline $41-50$ & 1 & 4 & & 1 & & 6 & 1 & 1 & & & 2 & 10 & 5 & & 2 & 33 \\
\hline $51-60$ & 4 & 6 & 1 & & 2 & 5 & & 1 & 1 & 3 & & 10 & 3 & 2 & & 38 \\
\hline $61-70$ & 2 & 13 & & & 1 & 5 & & 2 & & & & 8 & 1 & 2 & 1 & 35 \\
\hline $71-90$ & 2 & 3 & 4 & 2 & & 2 & 1 & & & 1 & 1 & 5 & & & & 21 \\
\hline Total & 12 & 30 & 5 & 3 & 6 & 27 & 3 & 4 & 2 & 4 & 4 & 68 & 25 & 4 & 3 & 200 \\
\hline
\end{tabular}


Table:2 Types Of Histopathological Lesions In Oesophagus.

\begin{tabular}{|c|c|c|}
\hline Lesion & No. of cases & Percentage(\%) \\
\hline Benign Lesions & 20 & 40 \\
\hline Chronic non specific oesophagitis & 12 & 24 \\
\hline Metaplasia(Barrets oesophagus) & 3 & 6 \\
\hline Dysplasia & 5 & 10 \\
\hline Malignant Lesions & 30 & 60 \\
\hline Squamous Cell Carcinoma & 26 & 52 \\
\hline Adenocarcinoma & 4 & 8 \\
\hline
\end{tabular}

Table 3: Types Of Histopathological Lesions In Stomach.

\begin{tabular}{|c|c|c|}
\hline Type of Lesion & No. of Cases & Percentage(\%) \\
\hline Chronic non-specific gastritis & 27 & 54 \\
\hline Chronic gastritis with H.Pylori & 6 & 6 \\
\hline Erosive Gastritis & 3 & 8 \\
\hline Chronic gastritis with intestinal metaplasia & 4 & 8 \\
\hline Chronic gastritis with dysplasia & 4 & 4 \\
\hline Gastric Polyp & 2 & 8 \\
\hline Gastric malignancy & 4 & \\
\hline
\end{tabular}

Table 4: Types of Histopathological Lesions In Duodenum (According to Marsh Classification ${ }^{[7]}$ ).

\begin{tabular}{|c|c|c|}
\hline Type of lesion & No. of cases & Percentage (\%) \\
\hline Benign Lesions & 93 & 63 \\
\hline Non-specific Duodenitis & 68 & 2 \\
\hline Type I & 2 & 6 \\
\hline Type II & 6 & 10 \\
\hline Type IIIA & 10 & 7 \\
\hline Type IIIB & 7 & 4 \\
\hline Malignant Lesions & 4 & 3 \\
\hline Adenocarcinoma & 3 & 1 \\
\hline Neuroendocrine tumour & 1 & 3 \\
\hline
\end{tabular}

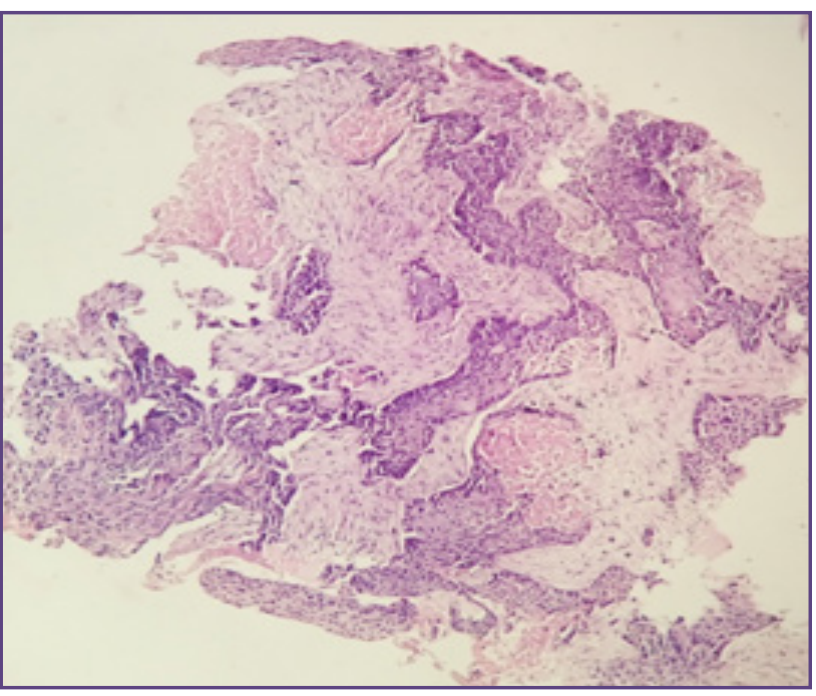

Fig. 1: Squamous Cell Carcinoma, moderately differentiated, Oesophagus. (10x, H\&E Stain).

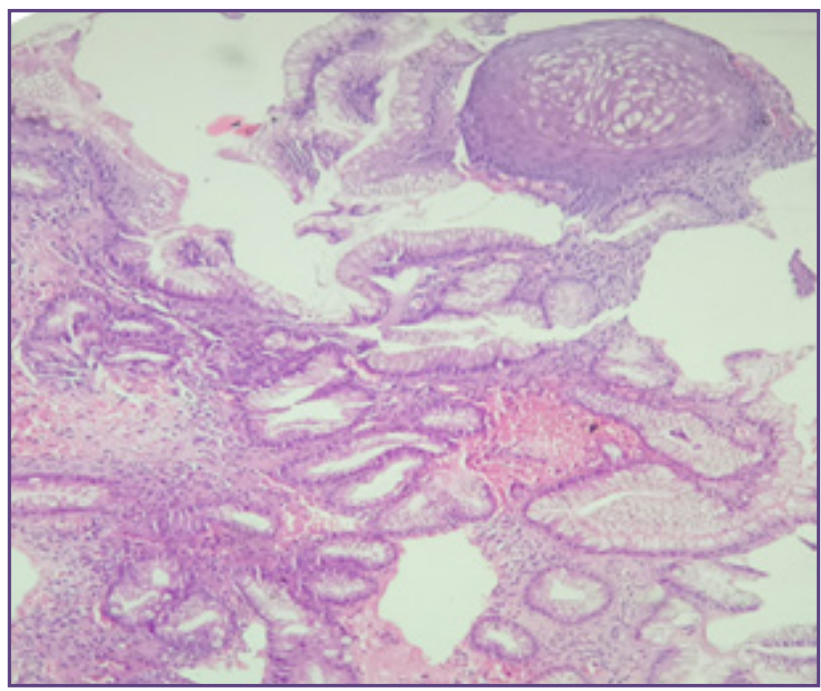

Fig. 2: Barret's Oesophagus (10x, H\&E stain). 


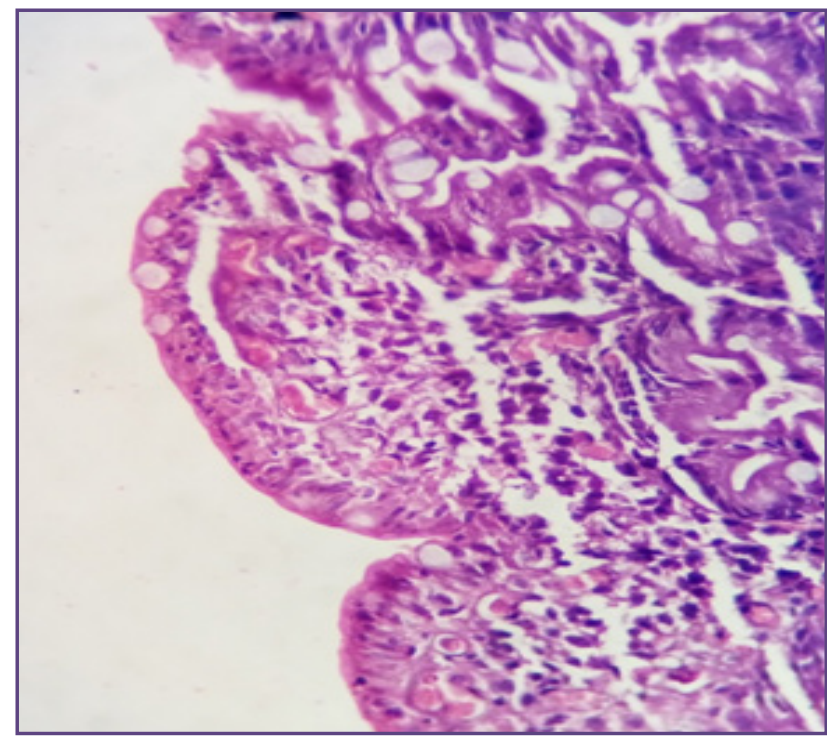

Fig. 3: Celiac Disease, IIIB (40x, H\&E stain).

\section{Discussion}

Upper gastrointestinal lesions most commonly present as dyspepsia, dysphagia, heart burn and pain in upper abdomen. Endoscopy followed by biopsy forms an important tool in the diagnosis of premalignant lesions and detection of malignancy at an early stage, thus reducing the overall morbidity and mortality. Proper visualization with precise selection of site of biopsy followed by accurate histopathological interpretation with clinical correlation is the mainstay for diagnosis and clinical management.

In the present study out of total 200 cases, the most common site of biopsy was second part of duodenum (50\%) followed by stomach (25\%) and oesophagus (25\%). Majority of cases were of male gender with a male to female ratio of 1.3:1. This is in accordance with studies done by Aparajita $\mathrm{A}$ et $\mathrm{a}^{[8]}$ and Gumber $\mathrm{R}$ et $\mathrm{a}^{[9]}$. Age group in which maximum biopsies were performed was $51-70$ years (36.5\%) which is similar to studies done by Aparajita A et al, ${ }^{[8]}$ Qureshi et al, ${ }^{[10]}$ Frank et al ${ }^{[11]}$ and Piyaporn et al. ${ }^{[12]}$ More number of biopsies in this age group may be due to more chances of neoplastic lesions in elderly age and due to variable risk factors in different age groups.

Majority of the lesions (153/200, 76.5\%) of upper gastrointestinal tract were non-neoplastic in the present study. Gulia SP et al ${ }^{[13]}$ also reported 168 non- neoplastic lesions out of total 192 upper gastrointestinal biopsies $(87.5 \%)$ in consensus with the present study.

\section{Distribution of Oesophageal Lesions}

Malignant lesions were more common accounting for $60 \%$ of the total oesophageal biopsies while $40 \%$ were nonneoplastic lesions. Similar findings were observed in studies done by Gumber R et a ${ }^{[9]}$ and Aparajita $\mathrm{A}$ et al. ${ }^{[8]} \mathrm{A}$ higher prevalence of malignancy was reported by Sheikh BA et al ${ }^{[14]}$ and Memon $\mathrm{F}$ et al ${ }^{[15]}$ being $82 \%$ and $78.6 \%$ respectively. Squamous cell carcinoma (86.6\%) (Fig. 1) was the most common histological type in malignant lesions which is comparable to various studies ${ }^{[8,9,14,16]}$ ranging from $66 \%$ to $100 \% .63 .3 \%$ of patients with oesophageal carcinoma were in 51-70 yrs. These observations are similar to studies done by Abhilash SC et a ${ }^{[16]}$ and Qureshi et al. ${ }^{[10]}$

Chronic Non specific oesophagitis (24\%) was the commonest diagnosis amongst the non neoplastic lesions similar to study by Gulia SP et al. ${ }^{[13]}$ Barrets oesophagus, a premalignant condition, was seen in $6 \%$ of cases. Abhilash SC ${ }^{[16]}$ reported 5.3\% and Gumber $\mathrm{R}$ et al ${ }^{[9]}$ reported $4.4 \%$ cases of Barrets oesophagus. The occurrence of specialized columnar epithelium lining a segment of distal esophagus above the level of the lower esophageal sphincter is referred to as Barrett esophagus.(Fig.2) This change is acquired and the result of ulceration and subsequent re-epithelization by columnar cells of what originally was esophageal squamous mucosa. The ulceration is nearly always induced by gastroesophageal reflux and is said to occur in $10 \%$ of patients with this condition. The ultimate origin of the columnar cells remains uncertain; theoretically, they could arise from migration of gastric mucosa, as a result of a phenotypic switch of undifferentiated elements in the stem cell mucosal population, or as a repopulation from underlying submucosal glands. The main complications of Barrett esophagus are peptic ulcer, stricture, bleeding plus the development of dysplasia and adenocarcinoma. Dysplasia is found in Barrett esophagus in the absence of carcinoma in $5-10 \%$ of the cases and in association with carcinoma in $68-100 \%$ of the cases. Risk for development of invasive carcinoma in patients with dysplasia in Barret's oesophagus is estimated to be 30 to 40 fold higher than in general population. ${ }^{[17]}$ Thus the identification of this lesion is important and endoscopic biopsy is a successful tool for the same.

Distribution of Gastric Lesions: In the present study, overall inflammatory lesions (88\%) were more common in gastric biopsies and chronic non-specific gastritis (54\%) was the most common diagnosis. Memon $\mathrm{F}$ et $\mathrm{al}^{[15]}$ and Gumber $\mathrm{R}$ et $\mathrm{al}^{[9]}$ also showed similar trends. H.pylori gastritis was seen in $12 \%$ of cases. In various studies done H.pylori gastritis has been reported variably ranging from $3.9 \%$ to as high as $36 \%{ }^{[8,9,13,15,16,18]}$ The wide variation may be due to the subjective variation, density of the organism and low sensitivity of H\&E stain along with Giemsa stain to identify the bacteria. In one study, Polymerase Chain Reaction (PCR) detected H. pylori in about 20\% of histologically negative gastric biopsies ${ }^{[19]}$ Medical therapy 
can lead to eradication of the organism and a regression of the inflammatory changes in the mucosa. ${ }^{[17]}$ As there was no history available for previous medications by the patient, this could also be a contributory factor for the low incidence of H.Pylori gastritis in the present study. Gastritis with intestinal metaplasia or dysplasia is an important histological finding as it denotes a premalignant condition. In $16 \%$ of cases, intestinal metaplasia/dysplasia was seen along with gastritis. Similar observation was also made by Abhilash SC et al. ${ }^{[16]}$ Only $8 \%$ of gastric biopsies were diagnosed as malignancy on histology, adenocarcinoma being the histological type. Memon F et al, ${ }^{[15]}$ Gulia SP et $\mathrm{al}^{[13]}$ and Abhilash $\mathrm{SC}$ et $\mathrm{al}^{[16]}$ also reported a lower prevalence of malignancy, frequencies of 5\%,6.1\% and $14.7 \%$ respectively. In contrast, studies done by Krishnappa $\mathrm{R}$ et al ${ }^{[18]}$ Gumber $\mathrm{R}$ et al ${ }^{[9]}$ reported $27.9 \%$ \& $29 \%$ cases of malignancy respectively. Although the incidence of gastric carcinoma is comparatively lower in India than in other countries, a high incidence has been noted in Southern India, particularly in Chennai. ${ }^{[20]}$ Aparajita A et $\mathrm{al}^{[8]}$, Qureshi et al ${ }^{[10]}$ and Gulia SP et $\mathrm{al}^{[13]}$ also reported adenocarcinoma as the most common histological type in gastric carcinoma similar to the present study.

Distribution of Duodenal Lesions: Non- specific duodenitis (68\%) was the most common lesion encountered in duodenum. Duodenum has a rich rapidly regenerating epithelial lining which can easily be affected by any inflammatory insult. ${ }^{[15]}$ Inflammatory lesions are more common in duodenum was also shown by studies done by Abhilash SC et al, ${ }^{[16]}$ Khandelia $\mathrm{R}$ et $\mathrm{al}^{[21]}$ and Shepherd NA et al. ${ }^{[22]}$ Coeliac disease (Fig.3) was seen in 25\% of cases. The currently used grading system of celiac disease in small bowel biopsies is a modification of the Marsh ( Marsh - Oberhuber) criteria adopted by the National Institutes of Health. ${ }^{[7]}$

Grade $0=$ normal

Grade 1 = Intraepithelial lymphocyte (IELs) only

Grade 2 = IELs plus crypt proliferation

Grade 3a, b, c = mild, moderate, and severe shortening of villi, respectively.

Increased intraepithelial $\mathrm{T}$ lymphocytes, although far from being pathognomonic, are a clue to the diagnosis in specimens in which villous atrophy may not be evident It should be emphasized that villous atrophy is not pathognomonic of celiac disease. ${ }^{[17]}$ In present study Type IIIA $(10 \%)$ was the most common and Type I $(2 \%)$ was the least common. This is in contrast to findings of Farzana
Memon ${ }^{[15]}$ who reported a high suspicion of celiac disease in $76.1 \%$ of cases amongst which mild celiac disease was more common(35\%). Small tissue biopsy and fragmented bits make the identification of IELs difficult which may be the cause for less number of type I disease in the present study. In the upper gastrointestinal lesions, duodenum presented with the least number of malignant cases $(4 \%)$. This could not be compared with other studies as the numbers of duodenal biopsies included were very less in the various studies.

\section{Conclusion}

In present study the commonest site of endoscopic biopsy was from duodenum. Overall inflammatory lesions were common, most common being chronic non-specific duodenitis. In $4.5 \%$ of cases premalignant lesions were identified and malignancy was identified in $19 \%$ of cases, oesophagus being the most common site of malignancy. Malignant lesions were more common in sixth decade. Thus, ulcerative or fibrotic lesions in oesophagus must always be biopsied to rule out a malignant etiology. Endoscopy is a least invasive, daycare procedure which when combined with endoscopic biopsy helps to identify and classify the various upper gastrointestinal lesions along with the premalignant lesions. Biopsy tissue can also be further used for Immunohistochemistry in malignant lesions.

\section{Reference}

1. Varadaraju S, et al: The yield and the predictors of esophageal pathology when upper endoscopy is used for the initial evaluation of dysphagia. Gastrointest Endosc.2005 June; 61(7):804-8.

2. Suvakovic Z, Bramble MG, Jones R, Wilson G, Idle N, Ryott J. Improving the detection rate of early gastric cancer requires more than open access gastroscopy: a five year study. GUT 1997; 41(3):308-13

3. Barr H. Endoscopic screening for upper gastrointestinal malignancy. In: Westby D, Lombard M, editors. Therapeutic Gastrointestinal Endoscopy. UK: Martin Dunitz Ltd; 2002 $: 54-6$

4. Nowshad Khan, Ghulam Shabbir, Muham. Upper Gastrointestinal Endoscopic Assessment of Patients Presenting With Dyspepsia. JPMI 2007; 21(3):212-216.

5. Kreuning J, Osman FTB, Kuiper G, A. M. v.d. Wal, J. Lindeman. Gastric and duodenal mucosa in 'healthy' individuals an endoscopic and histopathological study of 50 volunteers. Journal of Clinical Pathology, 1978, 31, 69-77.

6. Afzal S, Ahmad M, Mubarik A, Saaed F, Rafi S, Saleem N, Hussain A. Morphological spectrum of gastric lesionsEndoscopic biopsy findings. Pak Armed force Med J. 2006 june; 56(2):143-9.

7. Oberluber G, Granditsch G, Voselrang H; The histopathology of celiac disease; time for a standardized report scheme 
for pathologist, European Journal of gastroenterology and hepatology 1999; 11:1195-1194.

8. Aparajita A, Mohanty RC, Sahu AA, Mohanty R, Satpathy PK, Bhuyan T. Histomorphological study of upper GI endoscopic biopsies. Int J Health Sci Res. 2016; 6(12):59-64.

9. Gumber R, Mulay SS. Endoscopic Biopsy Interpretation of Upper Gastrointestinal Pathologies. International Journal Of Scientific Research. 2016 Oct; Vol 5 (10):20-24.

10. Qureshi NA, Hallissey MT, Fielding JW. Outcome of index upper gastrointestinal endoscopy in patients presenting with dysphagia in a tertiary care hospital-A 10 years review. BMC Gastroenterology 2007; 7:43.

11. Sacco F, Bruce MG, McMahon BJ, Bruden D. A prospective evaluation of 200 upper endoscopies performed in Alaska native persons. International Journal of Circumpolar Health 2007; 66(2):144-52.

12. Choomsri P, Bumpenboon W, Wasuthit Y, Euanorasetr C, Sumitpradit P, Suwanthunma W. Upper gastrointestinal endoscopy findings in patients presenting with dyspepsia. The Thai journal of Surgery 2010; 31:7-12

13. Gulia SP, Chaudhury M, Noorunnisa N, Balakrishnan CD, Balagurunathan K. Interpretation of Upper Gastro Intestinal Tract Endoscopic Mucosal Biopsies - A Study Conducted in Teaching Hospital In Puducherry, India. Int J Med Health Sci. July 2012; Vol-1(3):17-24.

14. SheikhBA,HamdaniSM,MalikR.Histopathologicalspectrum of lesions of upper gastrointestinal tract - A study of endoscopic biopsies. Gjmedph 2015; Vol. 4(4):1
15. Memon F, Baloch K, Memon AA. Upper gastrointestinal endoscopic biopsy; morphological spectrum of lesions. Professional Med J 2015; 22(12):1574- 1579.

16. Abilash SC, Kolakkadan H, Gitanjali MM, Shreelakshmidevi S, Balamuruganvelu S. Histopathologic Spectrum of Upper Gastrointestinal Tract Mucosal Biopsies: A Retrospective Study. Sch. J. App. Med. Sci. May 2016; 4(5E):1807-1813.

17. Rosai J In:Rosai and Ackerman's Surgical Pathology. 10th ed. Elsevier: Mosby;2011:673-713.

18. Krishnappa R, Horakerappa MS, Karar A, Mangal G. A study on histopathological spectrum of upper gastrointestinal tract endoscopic biopsies. Int J Med Res Health Sci. 2013; 2(3):418-424

19. Zsikla V, Hailemariam S, Baumann M, Mund MT, Schaub $\mathrm{N}$, Meier R, Cathomas G. Increased rate of Helicobacter pylori infection detected by PCR in biopsies with chronic gastritis. Am J Surg Pathol 2006; 30:242-248.

20. Gajalakshmi V, Swaminathan R, Shanta V. An independent survey to assess completeness of Registration: Population based cancer registry, Chennai, India. Asian Pac J Cancer Prev 2001; 2:179-83

21. Khandelia R, Saikia M. Histopathologic Spectrum of Upper Gastrointestinal Tract Mucosal Biopsies: A Prospective Study. International Journal of Medical Science and Clinical Inventions. 2017; 4(11): 3314-3316.

22. Shepherd NA, Valori RM. Guidance for Endoscopic Biopsy in the Gastrointestinal Tract Frontline. Gastroenterology. 2014; 5(2): 84-87.

*Corresponding author:

Dr Anupama Dayal, B-62, Shakuntal Bungalows, Near Rajhans Cinema, Nikol-naroda road, Nikol. Ahmedabad. Gujarat. India.382350.

Phone: +91 9898264571

Email: dayal1.anupama.ad@gmail.com

Financial or other Competing Interests: None. 